\title{
USING SOCIAL NETWORK DATA TO IMPROVE PLANNING AND DESIGN OF SMART CITIES
}

\author{
RAQUEL PÉREZ-DELHOYO ${ }^{1}$, HIGINIO MORA² \& JOSÉ FRANCISCO PAREDES ${ }^{2}$ \\ ${ }^{1}$ Department of Building Sciences and Urbanism, University of Alicante, Spain \\ ${ }^{2}$ Specialized Processor Architecture-Laboratory, Department of Computer Science Technology and Computation, \\ University of Alicante, Spain
}

\begin{abstract}
The Smart City concept has transformed the meaning of citizen participation. Smart Cities are characterized by being inclusive cities, i.e., cities for all. But the concept of inclusive city refers both to make it easy for citizens to use urban spaces and to involve citizens in the planning, design and management of cities. Citizens leave a trace when using public space and this information can be known, thanks to the last technological advances in the field of Information and Communication Technology It is the citizens themselves who voluntarily make these data available via social networking websites. It is therefore a new form of public participation. Knowing the real citizens' use of public space is essential for the planning and design of Smart Cities. However, information in general is not and does not produce knowledge itself. Knowledge does not simply come from having access to large amounts of information. It is necessary to understand the databases and structure the information to ensure proper use of it. This research delves into problem solving on how to collect and how to process this information. Specifically, this paper focuses on obtaining data from social networking websites relating to the sports field. The main goal of this research is to introduce a citizen-centric urban planning approach by analysing the possibilities offered by the citizen-generated data retrieved from social networks for sport. As a result, the graphic representation of aggregated geospatial information in an urban context is proposed in order to improve the decision-making process for its planning and design.

Keywords: Smart City, inclusive city, citizen participation, social network data analysis, technologyaided urban planning, citizen-centric urban planning.
\end{abstract}

\section{INTRODUCTION}

The Smart City concept would not make sense today without citizen participation. People are the main resource of cities in order to create competitive advantage [1], [2]. The knowledge society and the latest Information and Communication Technologies, allowing cities to move towards citizen-centric governance systems [3], have transformed the traditional meaning of citizen participation [4]. In this regard, the planning and design of cities of the future is a collective challenge today, which involves both governments and citizens [5].

Knowledge is an essential factor for the planning of Smart Cities. However, the idea of planning and designing cities, recognizing the power of creativity and imagination that are characteristic of the knowledge society has not been seriously considered as yet. We are witnessing a slow reformulation of the urban planning paradigm [6], [7]. A new approach to the discipline of citizen-centric urban planning, promoting engagement and active involvement in shaping the urban environment, is consistent with the principles and aims of the Smart City model that, in short, emerges as a reflection of the current knowledge society and its technological environment [8].

Smart Cities are characterized by being inclusive cities, i.e., cities for all. But the concept of inclusive city refers both to make it easy for citizens to use urban spaces and to involve citizens in the planning, design and management of cities. In this way, urban planning becomes a process where the city learns from itself, and from the people's habits, needs and desires. A process that uses the imagination and collective intelligence of citizens in order to 
co-create and shape the city of tomorrow. This citizen-centric approach is critical for the future of urban planning.

Within this context, social networks are a very valuable source of information. Citizens leave a trace when using public space and this information can be known, thanks to the last technological advances in the field of Information and Communication Technology it is the citizens themselves who voluntarily make these data available via social networking websites. It is therefore a new form of public participation. Knowing the real citizens' use of public space is essential for the planning and design of Smart Cities. However, information in general is not and does not produce knowledge itself. Knowledge does not simply come from having access to large amounts of information. It is necessary to understand the databases and structure the information to ensure proper use of it.

In line with this approach, this research delves into problem solving on how to collect and how to process this information. Specifically, this paper focuses on obtaining data from social networking websites relating to the sports field. In short, the main goal of this research is to introduce a citizen-centric urban planning approach by analysing the possibilities offered by the citizen-generated data retrieved from social networks for sport. As a result, the graphic representation of aggregated geospatial information in an urban context is proposed in order to improve the decision-making process for its planning and design.

The rest of the work is structured as follows: Section 2 gives a brief overview of the related work on the use of citizen-generated data retrieved from social networks as a source of information for improving urban planning, design and management; in Section 3, the main characteristics of a social network data analysis methodology for supporting citizen-centric urban planning are proposed; Section 4 explains the analysis developed on social networks relating to the sports field; and finally, in Section 5, some conclusions are drawn.

\section{RELATED WORK: A BRIEF OVERVIEW}

The study of urban places preferred, and people's movement patterns supports a better understanding of modern cities and enables a more comprehensive strategy for urban planning [10].

In line with this overall vision, a wide range of studies has been developed, for example using GPS data [11], mobile phone location data [12], [13], or smart card data [14]. The study of the citizens' mobility has seen significant growth due the prevalence of mobile devices. By combining these data with the city's points of interests both travel patterns and purposes can be known. Some studies also propose new algorithms which can identify trajectories from origin-destination data [15].

A good deal of recent research concerns locative social networks as open sources of data to acknowledge which city places are preferred, used and liveable. Some of these studies propose methodologies, for example to identify city's successful public spaces through the location-based social-media network Foursquare [16]; to discover popular tourist attractions within the urban areas through the Flickr geotagged images [17]; or to depict urban boundaries with geo-located Twitter data [18]. Other studies focus on how visualization of social network data allows researchers to explore the relationship between citizens' movements and activity distributions that are characterized by the points of interest [19]; some of them propose novel data representations such as graphs to characterize spatial and temporal people mobility [20]. In addition, some studies propose visual analytics systems to measure opinion propagation, for example among Twitter users [21], and others focus on the analysis of urban emotions [22], [23]. 
Other research in the field of Internet of Things proposes generic solutions for the smart urban planning, smart city architectures which are based on Big Data analytics [24], [25] and smart strategies for developing more resilient and sustainable cities [26], [27].

\section{CHARACTERISTICS OF A SOCIAL NETWORK DATA ANALYSIS}

METHODOLOGY FOR SUPPORTING CITIZEN-CENTRIC URBAN PLANNING

The knowledge needed to city planning includes the physical, social, cultural, technological and economic domains, and incorporates multiple perspectives, such as the understanding of social and cultural dynamics and needs, to create new knowledge [28].

The different urban fabrics, public spaces, facilities and services resulting from planning, should be the consequence of the sum of the experiences and priorities of citizens living in a city [29]. A new understanding of urban abilities and opportunities and a new way of working to maximize their potential emerge from all these experiences.

To think first about the people's culture and the daily activities they perform and then about their needs and desires, i.e., to develop a flexible and inclusive human environment where people are the center is a beginning in the reformulation of the urban planning paradigm [30].

The concept of City is dynamic, not static, so an urban planning model has to see the city as a living organism. It has to be more a continuous process of being alert to opportunities than a detailed plan. This means that the city becomes a canvas and scene for human activities and, consequently, urban planning has to move towards a citizen-centric model.

For this reason, the availability of information on citizens' habits, preferences, needs and desires is essential for the planning and design of cities [31]. Citizen-generated data analysis methodologies are needed for supporting citizen-centric urban planning. Some essential characteristics for these methodologies to be reliable and effective are introduced below.

- Ability to identify the public space preferred and used by citizens.

- Ability to determine the way in which citizens use urban public space: traceability - determining and following the path of a citizen - the duration of stay in a place, places frequently visited.

- Ability to identify how citizens experience the city: their habits, preferences, daily needs and desires.

- Ability to identify the different ways in which people can connect, interact and meet.

- Ability to identify the atmosphere generated within the city because of the activities taking place.

- Ability to connect patterns, take advantage of experiences and practices that have been tested by citizens.

- Ability to visualize possible futures taking into account the preferences of citizens.

- Pay attention and respond to the diversity of identities, needs and abilities of people.

- Ability to identify social and cultural dynamics in cities.

4 ANALYSIS ON SOCIAL NETWORKS RELATING TO THE SPORTS FIELD

This work is focused on sport social network analysis. In these networks, the users contribute with information about their sport activities, and they post data on scores, times and routes where they take their activity. The data on these aspects are voluntarily introduced by the users themselves with the aim of sharing their experiences with other users.

The generation of data and communication to the social network is usually done automatically through users' mobile devices, such as smart watches, smart phones and other 
wearables provided with Global Positioning System (GPS) devices capable of drawing the route on a map.

\subsection{Social networks for sport}

We have explored some of the most popular sites on this subject in order to know their features and the variability of the information collected. Table 1 describes the main social networks analyzed.

All the previous networks provide search services for places to play sports and consult the best routes in each place.

In addition, they offer premium services for registered users that include additional functionalities, such as the creation of training plans, advanced sports performance statistics, health guides and even access to personal trainer advices.

\subsection{Data visualization}

All the analyzed sites provide information of the routes followed by their users in the practice of their sport. These routes can be accessed and displayed directly through a web interface for a desktop-computer browser or through an 'App' for a mobile device.

In this work, we have analyzed the routes of the citizens that include the activities of walking, fast-walking, hiking and running.

Fig. 1 shows the interface focused on Alicante city Spain, provided by the social network analyzed.

The analysis of the routes stored in social networks allows us to identify urban areas where sports activities are played. A simple search through the web interface gives us the map where the routes are generated.

These routes can be easily downloaded from the previous pages in various structured geopositioning formats - KML, GPX, TCX, GTM.

Table 1: Social networks for sport.

\begin{tabular}{|l|l|}
\hline \multicolumn{1}{|c|}{ Company } & \multicolumn{1}{|c|}{ Description } \\
\hline $\begin{array}{l}\text { Mapmyrun } \\
\text { http://www.mapmyrun.com }\end{array}$ & $\begin{array}{l}\text { Social network to share the } \\
\text { sports activity linked to the } \\
\text { sports products company } \\
\text { Under Armor. }\end{array}$ \\
\hline $\begin{array}{l}\text { Strava } \\
\text { https://www.strava.com }\end{array}$ & $\begin{array}{l}\text { Social network to share } \\
\text { activities with a broad social } \\
\text { community of registered users }\end{array}$ \\
\hline $\begin{array}{l}\text { Runtastic } \\
\text { https://www.runtastic.com }\end{array}$ & $\begin{array}{l}\text { Social network to track and } \\
\text { manage health and fitness data }\end{array}$ \\
\hline
\end{tabular}




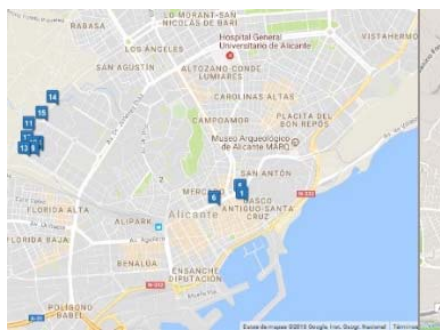

(a)

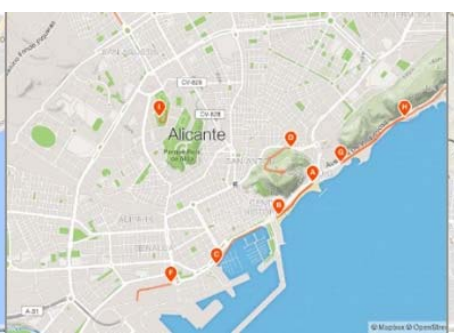

(b)

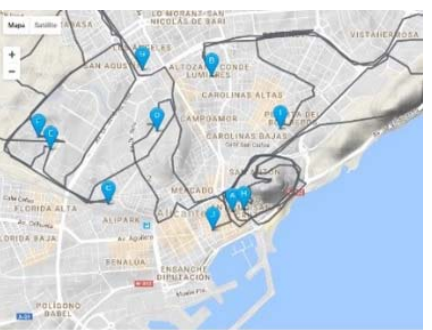

(c)

Figure 1: Route visualization interface for Alicante city. (a) Mapmyrun; (b) Strava; (c) Runtastic.

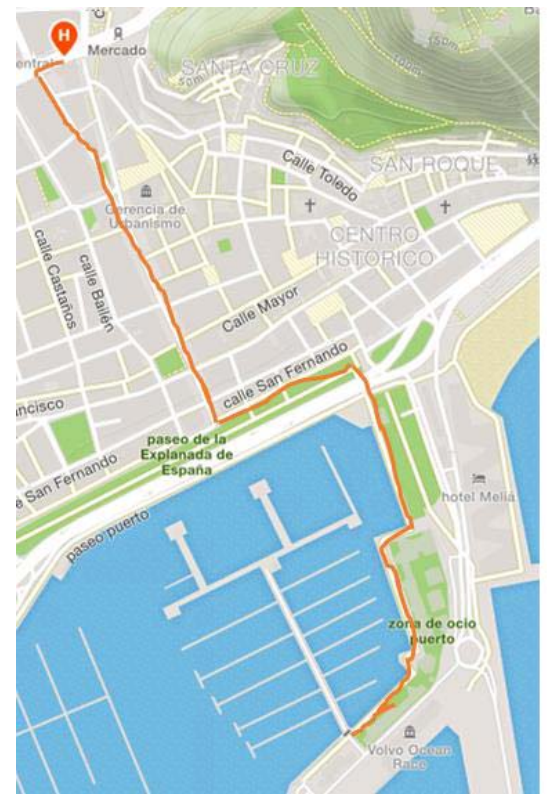

(a)

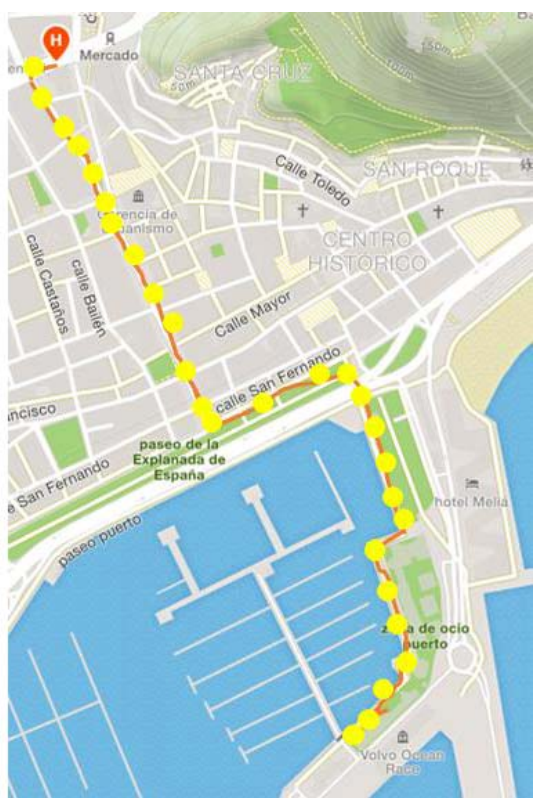

(b)

Figure 2: (a) Route example matching (b) Route points (Source: Data retrieved from Strava.)

Table 2: $\quad$ List of places generated. (Source: Authors' own table based on data retrieved from Strava.)

\begin{tabular}{|l|c|}
\hline Place & Matches \\
\hline Central Market of Alicante & 1 \\
Méndez Núñez Avenue & 12 \\
Explanada de España promenade & 6 \\
Port of Alicante & 6 \\
Port entertainment area & 5 \\
Volvo Ocean Race area & 2 \\
\hline
\end{tabular}


However, for an automated analysis it is necessary to download the routes and process them through massive analysis techniques. The social networks analysed provide computer tools that allow developing applications based on the information they have. To that end, they provide a specific Application Programming Interface (API) to access the services offered.

Among the operations they provide, is the query of bunch of routes. In this way, you can obtain route collections for massive analysis of any given city and geographic area.

Grouping of routes and characterization of common routes is done through computational methods by comparing the points of the route and the geolocated positions of the city. In this way, each point of the route is associated to a place in the city such as a street, promenade, plaza or road, where the sport has been played. The following figure (Fig. 2) illustrates this process for an example tour.

After the process of comparing the set of selected routes, a list of common places frequented by citizens in the exercise of their activity is generated. For example, the following table (Table 2) shows the list of matches that is produced as a result of the analysis of the route drawn in previous figure (Fig. 2).

\section{CONCLUSIONS}

We are witnessing a reformulation of the paradigm of urban planning towards a new, more open and participatory approach focused on citizens. Citizen-generated data retrieved from social networks are essential for supporting citizen-centric urban planning. In this work an analysis of the possibilities offered by some social networks relating to the sports field has been conducted, which concludes that in these web platforms there is large amounts of useful information available for the planning and design of cities. This knowledge of the human scale provides researchers and planners with a more complete vision of the city and therefore allows them to make better decisions in matters that affect citizens.

\section{ACKNOWLEDGEMENT}

This work has been funded by the Conselleria de Educación, Investigación, Cultura y Deporte, of the Community of Valencia, Spain, within the program of support for research under project $\mathrm{AICO} / 2017 / 134$.

\section{REFERENCES}

[1] Florida, R., Cities and the Creative Class, Routledge, 2005.

[2] Cossetta, A. \& Palumbo, M., The co-production of social innovation: The case of living lab, Smart City. How to Create Public and Economic Value with High Technology in Urban Space, Springer, pp. 221-236, 2014.

[3] Goldsmith, S. \& Crawford, S., The Responsive City: Engaging Communities Through Data-smart Governance, John Wiley \& Sons, 2014.

[4] Castells, M., The Rise of the Network Society: The Information Age: Economy, Society, and Culture, 1, John Wiley \& Sons, 2011.

[5] Oliveira, A. \& Campolargo, M., From smart cities to human smart cities, System Sciences (HICSS). Proceedings of 48th Hawaii International Conference on System Sciences, IEEE, pp. 2336-2344, 2015.

[6] Landry, C., The Changing Face of Urban Planning: Towards Collaborative and Creative Cities. Human Smart Cities. Rethinking the Interplay between Design and Planning, Springer, pp. 238-250, 2016. 
[7] Marsal-Llacuna, M.L., Leung, Y.T. \& Ren, G.J., Smarter urban planning: match land use with citizen needs and financial constraints. International Conference on Computational Science and Its Applications, Springer, pp. 93-108, 2011.

[8] Mueller, J., Lu, H., Chirkin, A., Klein, B. \& Schmitt, G., Citizen Design Science: A strategy for crowd-creative urban design. Cities, 72, pp. 181-188, 2018.

[9] OECD, Making Cities Work for All: Data and Actions for Inclusive Growth, OECD Publishing: Paris, 2016.

[10] Gonzalez, M.C., Hidalgo, C.A. \& Barabasi, A.L., Understanding individual human mobility patterns. Nature, 453(7196), pp. 779-782, 2008.

[11] Chen, Z., Gong, X. \& Xie, Z., An analysis of movement patterns between zones using taxi GPS data. Transactions in GIS, 21(6), pp. 1341-1363, 2017.

[12] Lu, S. et al., Understanding the representativeness of mobile phone location data in characterizing human mobility indicators. ISPRS International Journal of GeoInformation, 6(1), p. 7, 2017.

[13] Korpilo, S., Virtanen, T. \& Lehvävirta, S., Smartphone GPS tracking - Inexpensive and efficient data collection on recreational movement. Landscape and Urban Planning, 157, pp. 608-617, 2017.

[14] Bao, J., Xu, C., Liu, P. \& Wang, W., Exploring bikesharing travel patterns and trip purposes using smart card data and Online Point of Interests. Networks and Spatial Economics, 17(4), pp. 1231-1253, 2017.

[15] Bahbouh, K., Wagner, J.R., Morency, C. \& Berdier, C., Travel demand corridors: Modelling approach and relevance in the planning process. Journal of Transport Geography, 58, pp. 196-208, 2017.

[16] Martí, P., Serrano-Estrada, L. \& Nolasco-Cirugeda, A., Using locative social media and urban cartographies to identify and locate successful urban plazas. Cities, 64, pp. 66-78, 2017.

[17] Peng, X. \& Huang, Z., A novel popular tourist attraction discovering approach based on geo-tagged social media big data. ISPRS International Journal of Geo-Information, 6(7), p. 216, 2017.

[18] Yin, J., Soliman, A., Yin, D. \& Wang, S., Depicting urban boundaries from a mobility network of spatial interactions: A case study of Great Britain with geo-located Twitter data. International Journal of Geographical Information Science, 31(7), pp. 12931313, 2017.

[19] Zeng, W., Fu, C.W., Arisona, S.M., Schubiger, S., Burkhard, R. \& Ma, K.L., Visualizing the Relationship between human mobility and points of interest. IEEE Transactions on Intelligent Transportation Systems, 18(8), pp. 2271-2284, 2017.

[20] Wu, F., Zhu, M., Wang, Q., Zhao, X., Chen, W. \& Maciejewski, R., Spatial-temporal visualization of city-wide crowd movement. Journal of Visualization, 20(2), pp. 183194, 2017.

[21] Xu, P. et al., Visual analysis of topic competition on social media. IEEE Transactions on Visualization and Computer Graphics, 19(12), pp. 2012-2021, 2013.

[22] Resch, B., Summa, A., Zeile, P. \& Strube, M., Citizen-centric urban planning through extracting emotion information from Twitter in an interdisciplinary space-timelinguistics algorithm. Urban Planning, 1(2), pp. 114-127, 2016.

[23] Resch, B., Summa, A., Sagl, G., Zeile, P. \& Exner, J.P., Urban emotions: Geo-semantic emotion ex-traction from technical sensors, human sensors and crowdsourced data. Progress in Location-based Services, 2014, Springer, pp. 199-212, 2015.

[24] Babar, M. \& Arif, F., Smart urban planning using Big Data analytics to contend with the interoperability. Internet of Things, 77, pp. 65-76, 2017. 
[25] Jiang, H., Li, Q., Zhou, X., Chen, Y., Yi, S., Wang, H. \& Lu, Z., A collective human mobility analysis method based on data usage detail records. International Journal of Geographical Information Science, 31(12), pp. 2359-2381, 2017.

[26] Falco, G.J., City resilience through data analytics: A human-centric approach. Procedia engineering, 118, pp. 1008-1014, 2015.

[27] Mora, H., Gilart-Iglesias, V., Pérez-delHoyo, R. \& Andújar-Montoya, M.D., A comprehensive system for monitoring urban accessibility in Smart Cities. Sensors, 17(8), p. 1834, 2017.

[28] Zeile, P., Resch, B., Exner, J.P. \& Sagl, G., Urban emotions: benefits and risks in using human sensory assessment for the extraction of contextual emotion information in urban planning. Planning Support Systems and Smart Cities, Springer, pp. 209-225, 2015.

[29] Marsal-Llacuna, M.L. \& Fabregat-Gesa, R., Modeling citizens' urban time-use using adaptive hypermedia surveys to obtain an urban planning, citizen-centric, methodological reinvention. Time \& Society, 25(2), pp. 272-294, 2016.

[30] Brenner, N., Marcuse, P. \& Mayer, M., Cities for People, Not for Profit: Critical Urban Theory and the Right to the City, Routledge, 2012.

[31] de Oliveira, A.D., The human Smart Cities manifesto: a global perspective, human Smart Cities. Rethinking the Interplay between Design and Planning, Springer, pp. 197-202, 2016. 